\title{
REINATA SADIMBA, PAULINA CHIZIANE, ISABELA FIGUEIREDO - CORPOS RESISTENTES QUE CONTAM E MULTIPLICAM HISTÓRIAS
}

\author{
REINATA SADIMBA, PAULINA CHIZIANE, \\ ISABELA FIGUEIREDO - \\ RESISTANT BODIES THAT TELL \\ AND MULTIPLY STORIES
}

\author{
Renata Flaiban Zanete ${ }^{1}$ \\ Viviane Almeida ${ }^{2}$
}

\section{RESUMO}

O presente artigo busca como objetivo geral destacar certos trabalhos artísticos que refletem sobre o corpo feminino. Pretende, especificamente, observar como agressões impostas ao corpo das mulheres são reveladas, nomeadamente, nas obras da escritora Paulina Chiziane, da escultora Reinata Sadimba, ambas moçambicanas, e da escritora Isabela Figueiredo, portuguesa, nascida em Lourenço Marques. A escrita e a modelagem do barro apresentam-se como territórios onde as revelações ocorrem, na exposição de feridas, na denúncia de abusos e ao pensar a condição feminina, seja em sociedades tradicionais africanas, seja no chamado mundo moderno, durante e após o colonialismo português. Os objetivos das denúncias destas artistas podem ser encarados, portanto, como catalisadores de resistências e impulsionadores de um novo contexto, no qual as agressões ao corpo feminino sejam ao menos nomeadas e exibidas, a fim de poderem, quem sabe um dia, serem ultrapassadas. A violência que recai sobre Moçambique, no passado e no presente, reverbera nas obras de arte das mulheres aqui estudadas. As experiências pessoais das artistas, sentidas em seus corpos: na pele, no sexo, na boca e na língua que tentaram silenciar, nos ouvidos, nas palavras que lhes foram dirigidas por serem mulheres, tornaram-se rico material para a elaboração de suas obras, repletas de referências a estes corpos-alvo, atacados pela sociedade patriarcal, colonialista e misógina, em diferentes matizes e cenários geopolíticos.

PALAVRAS-CHAVE: Arte. Corpo Feminino. Resistência. Literatura. Sexualidade. 


\section{ABSTRACT}

The objective of this article is to highlight certain artistic works which reflect on the female body. Specifically, it intends to examine how aggressions and constraints imposed on women's bodies are revealed, namely, in the works of Mozambican writer Paulina Chiziane, Mozambican sculptor Reinata Sadimba, and Portuguese writer Isabela Figueiredo, who was born in Lourenço Marques. Their writing or modelling of clay presents itself as a territory for exposing wounds, denouncing abuse, and thinking about the female condition, whether in traditional African societies or the so-called modern world, both during and after Portuguese colonialism. The works of these artists can be seen, therefore, as catalysts of resistance and drivers of a new context, in which aggressions against the female body are at least named and exposed so that they may, one day, be overcome. The violence which has befallen Mozambique, in the past and the present, reverberates in the artworks of the women studied here. Felt in the body: the skin, the sex, the mouth and tongue they tried to silence, and the ears they filled with words addressed to them for being women; the personal experiences of the artists became rich material for the elaboration of their works. These works are replete with references to these target bodies in different hues and geopolitical scenarios, bodies which have been attacked by patriarchal, colonialist, and misogynistic society.

KEYWORDS: Art. Female body. Resistance. Literature. Sexuality.

"Quem já viajou no mundo da mulher? Quem ainda não foi, que vá. Basta dar um golpe profundo, profundo, que do centro vermelho explodirá um fogo mesmo igual à erupção de um vulcão.”

(Paulina Chiziane)

"Somos fugitivas de todos os bairros de zinco e caniço. Fugitivas das Munhuanas e dos Xipamanines, viemos do outro lado da cidade com nossos olhos espantados, nossas almas trancadas, nossos corpos submissos escancarados."

(Noémia de Sousa)

\section{INTRODUÇÃO}

Basta de ouvidos moucos, olhos tapados e bocas silenciadas, é o que as obras das artistas Reinata Sadimba, Paulina Chiziane e Isabela Figueiredo parecem nos dizer. Constroem suas obras a partir do sentido no corpo, por fora e por dentro: sofrimentos e agressões transformam-se em palavras e objetos que possam iluminar a trajetória de outras mulheres e homens, também envoltos nos dilemas apresentados pelas artistas, como uma espécie de denúncia de relações autoritárias, desiguais, que precisam ser revistas nos tempos que correm. ${ }^{3}$ 
Como referenciais teóricos iremos nos valer de autoras que refletem sobre o corpo da mulher, imerso na realidade patriarcal, produto e símbolo vivo dela e, ao mesmo tempo, inventor de outros mundos, por meio das linguagens artísticas. Autoras que trabalham a reflexão crítica como ofício literário e, por vezes, trazendo explicitamente à tona suas experiências pessoais, como: Gloria Anzaldúa (2017), Hélène Cixous (1995), Grada Kilomba (2019), Adrienne Rich (2002), entre outras.

\section{PRIMEIRAS APROXIMAÇÕES}

Reinata Sadimba (1945-) e Paulina Chiziane (1955-) são duas artistas moçambicanas contemporâneas. Reinata é de origem Makonde, do Norte, e Paulina de Gaza, ao Sul. As duas obtiveram destaque em seu país, e também fora dele, pelos trabalhos desenvolvidos no campo escultórico, no caso de Reinata, e na literatura, no caso de Paulina. O viver dentro da tradição, questioná-la e extrapolá-la, por meio do trabalho artístico, faz parte da trajetória de ambas. Reinata, dos potes utilitários na aldeia, para a criação de formas únicas, a mesclar representações de corpos humanos, principalmente femininos, em composições de toques surrealistas; Paulina, das narrativas ao pé do fogo, ouvidas da avó, para a criação literária de contos e romances.

Reinata Sadimba foi a primeira mulher escultora moçambicana reconhecida e é considerada como uma das mulheres mais importantes no terreno das artes de Moçambique. Tem realizado diversas exposições em museus e galerias de arte em vários países. As peças de Sadimba refletem profundamente o universo matrilinear Makonde ${ }^{4}$, reconfigurado através de desafiantes experiências pessoais e de um imaginário fértil, abordando, de forma simultaneamente moderna e tradicional, os temas da identidade individual - particularmente da mulher - e social, assim como da primordial ligação à terra.

Paulina queria ser pintora, quando jovem, mas a família e a sociedade a desencorajaram, incentivando-a a ser esposa e mãe. Participou da Frelimo ${ }^{5}$ e, desiludida com a política, enveredou pela escrita, como uma necessidade, atividade feita na madrugada, em muitas ocasiões quando cessavam os bombardeios, e após todos os outros trabalhos que são cobrados à mulher. Foi a primeira mulher a lançar um romance em Moçambique, em 1990, Balada de amor ao vento, encontrando resistências e críticas por parte da sociedade machista. O prêmio literário José Craveirinha que ganhou, em 2003, com Niketche: uma história de poligamia, fez com que ficasse mais conhecida, com edições de suas obras no Brasil e em Portugal. Seus romances apontam conflitos interculturais, estruturais da sociedade moçambicana, entre gêneros, religiosidades, a cultura tradicional e a sociedade moderna.

Isabela Figueiredo (1963-), nascida em Moçambique, escritora, professora de português no ensino secundário, fala-nos da quebra de um acordo tácito de segredo entre os colonos. Em seu livro Caderno de memórias coloniais, lançado em 2009 e prefaciado por Paulina Chiziane, na edição de 
2017, confronta o cenário idílico e memórias centradas na nostalgia dos colonos portugueses em Moçambique com suas histórias pessoais em torno de agressividades, confrontos étnico-raciais e culturais. Isabela é crua em sua narrativa e pergunta: "Aquilo que eu vi só eu é que vi? Os outros tinham os olhos tapados? Não pode ser."6.

\section{OS CORPOS NOS TEXTOS E AS INSCRIÇÕES DE FORMAS E PALAVRAS NOS CORPOS}

As marcas indeléveis nos corpos femininos são um símbolo da condição da mulher cristalizada em estruturas constrangedoras e mediada por relações familiares e sociais. Não obstante as amarras impostas, o corpo resiste e encontra novas formas de marcar a sua presença por intermédio das inscrições de formas e palavras.

Paulina Chiziane, em entrevista a Michel Laban (1998), fala de um concurso de escrita que ganhou na escola, quando criança. Segundo a freira da instituição, era mal escrito, mas tinha coração. A religiosa relaciona o texto de Chiziane a uma parte vital do corpo, que garantiu a aluna ter o texto premiado. Talvez a senhora quisesse dizer, com a palavra-imagem-coração que o texto tinha pulsação, ritmo, vida. A metáfora do coração nos faz ver a potência do texto que, mesmo na precocidade da vida da autora, já se revelava. (LABAN, 1998, p. 987).

Reinata Sadimba, exaustivamente, tem representado corpos: são mulheres com suas tatuagens faciais e a $n d o n a^{7}$ nos lábios. Mulheres que têm o corpo marcado pela tradição, mas que são também recriação, obras de arte como ponto de partida para imaginar e contar histórias. Histórias que os corpos, em relação uns com os outros, fazem emergir, no contato das obras com quem as observa. Histórias como a "da mulher que não quer ter cabeça" ${ }^{8}$, podem ser consideradas como transposições, para as artes plásticas, de narrativas do feminino.

Em "Cartografias do corpo", Isabela Figueiredo fala sobre um corpo que tem sido muito usado: "arranhadelas, queimaduras, cortes nas mãos, braços e pernas, por causa da cozinha, dos animais, de andar por aí metida a carregar, sempre em frente." (2014). Esta cartografia corporal proposta pela escritora revisita cicatrizes físicas e emocionais estabelecendo relações entre as marcas, de naturezas diferenciadas. Às marcas físicas, "acha-lhe[s] graça”, mas às dos sentimentos e emoções pretende, aos poucos, dia a dia, removê-las. Contudo, afirma que as únicas que realmente a preocupam "são as dos olhos, as que não consigo ver. Estão lá dentro." (2014).

A invisibilidade dos direitos dos corpos femininos, a sua existência sem violações e constrangimentos, muito mais do que uma questão datada num passado colonial, reverbera em obras e testemunhos contemporâneos como Memórias da plantação: episódios de racismo quotidiano (2019) da portuguesa Grada Kilomba (1968-). A artista plástica, performer, teórica e escritora reúne, neste livro, uma série de episódios do racismo quotidiano que 
não é um "ataque único" ou um "evento discreto", mas sim uma "constelação de experiências de vida", uma "exposição constante ao perigo," "um padrão contínuo de abuso" que se repete incessantemente ao longo da biografia de alguém - no ónibus, no supermercado, em uma festa, no jantar, na família. (KILOMBA, 2019, p. 80).

Kilomba destaca a boca ${ }^{10}$ como "o órgão da opressão por excelência"11 (KILOMBA, 2019, p. 33). A autora identifica uma dinâmica de interrupções, torturas de línguas, discursos impedidos e idiomas que são impostos e revindica a urgência da criação de uma nova linguagem, "um vocabulário no qual nos possamos todas/xs/os encontrar, na condição humana." (KILOMBA, 2019, p. 21). Grada é peremptória ao afirmar que

[a] literatura e a arte conseguem ter um discurso crítico, interromper um espaço e ocupá-lo. E fazem-nos ver coisas que não eram vistas antes. Há um desmantelamento da ignorância ${ }^{12}$.

A língua que se inventa, que não se submete, é sinal de resistência. Ann Rosalind Jones, intelectual estadunidense, assim se expressa: "[...] a resistência se manifesta na jouissance, isto é, na reexperiência directa dos prazeres físicos da infância e mais tarde da sexualidade, reprimida mas não obliterada pela Lei do Pai” (2002, p. 77). Nas histórias escritas de um modo peculiar, por Paulina Chiziane, temos a sua própria língua, uma escrita que descende da oralidade, que vem da boca e se inscreve no papel pela ação da mão. Chiziane, de língua materna chope, falava ronga com as amigas, na adolescência, e língua portuguesa na escola, o que deu origem a uma forma de falar que a escritora denomina de "pretuguês" (LABAN, 1998, p. 981).

Glória Anzaldúa (1942-2004), intelectual chicana, em seu artigo "Como domesticar uma língua selvagem", expõe como transitou entre diferentes línguas, algumas delas perseguidas e condenadas em escolas e universidades, até afirmar-se em sua identidade de muitas faces:

Não mais me farão sentir vergonha por existir. Terei a minha voz: índia, espanhola, branca. Terei a minha língua de serpente - a minha voz de mulher, a minha voz sexual, a minha voz de poeta. Ultrapassarei a tradição de silêncio. (ANZALDÚA, 2017, p. 232).

Chiziane também expõe este processo de afirmação de sua identidade, entre a tradição e o mundo europeu, que lhe foi imposto pela colonização e a escolarização católica. Diz por vezes sentir-se "flutuar entre os dois mundos" (LABAN, 1998, p. 975). Notamos que se afirma através de sua escrita: "Uma coisa que eu deixo muito clara: português padrão, nunca! Não estou interessada.” (LABAN, 1998, p. 982). Assumir-se como uma artista a escrever sobre relacionamentos amorosos e sexo também lhe trouxe desconfortos na sociedade patriarcal, como, por exemplo, de ser assediada por homens, em diferentes situações. A metáfora da bomba construída por si mesma, sobre sua cabeça, é bastante forte.

Ser mulher e ser artista torna-se um verdadeiro escândalo. Escândalo que tive que arriscar e suportar. Nesta sociedade a mulher só pode falar de amor e sexo com outras mulheres 
e também em segredo. Falar em voz alta é tabu, é imoral, é feio. No meu livro falo da vida, do amor e sexo. Com as minhas mãos accionei uma bomba sobre a minha cabeça. (CHIZIANE, 2013, p. 203).

Como salienta Jones, "Assumir uma posição como mulher poeta ou romancista é entrar num papel escrutinado por questões de autoridade, de público, de modos de publicação e distribuição." (2002, p. 93). É andar neste terreno minado, dominado por homens, no qual a mulher precisa lutar e se esforçar muito para conseguir se impor. É recusar as palavras que querem impor à mulher um papel restrito, dentro da sociedade.

No sentido apontado por Anzaldúa, é possível argumentar por esta "não domesticidade" do discurso de Chiziane, e também no imaginário expandido que Sadimba explora em suas figuras humanas, que saem do registro naturalista e das peças utilitárias, em busca de narrativas que se aproximam do sonho e do mítico, mesmo que conectadas com o quotidiano, em objetos concretos, feitos de barro.

Uma composição onírica emerge na figura feminina abaixo, na qual duas mãos circundam a cabeça, emoldurando sua máscara. Uma outra mão se insinua entre os seios, no ponto que pode ser considerado como centro das emoções. Mais outras duas mãos sustentam cabeças, que brotam de dentro do corpo feminino, e nos remetem aos filhos, tantas vezes carregados junto dos corpos de suas mães, no universo moçambicano tradicional. $\mathrm{O}$ ventre bojudo sustenta um corpo repleto de mãos, para atender a todas as demandas que são lançadas às mulheres.

Sem título, 2006

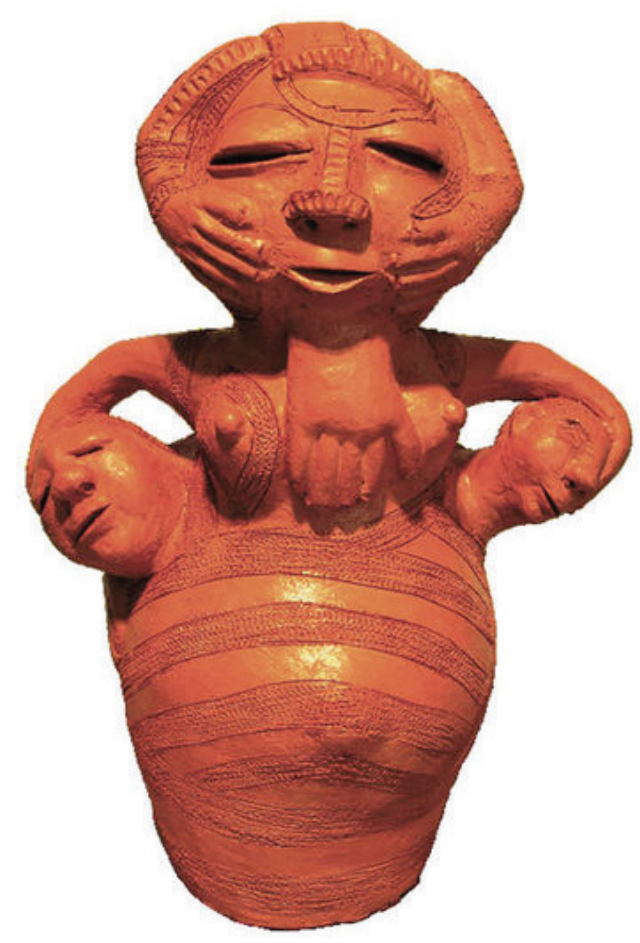

https://www.artsy.net/artwork/reinata-sadimba-untitled-37 
As obras das artistas aqui analisadas revelam como a sociedade patriarcal aborda o corpo feminino, com o apelo para que a mulher não veja, não ouça e fique calada. A escultura abaixo, de Reinata Sadimba, diz-nos isto claramente.

Obra sem título, patente na Exposição Comemorativa do 14 Aniversário da Perve Galeria - Lisboa - 2014

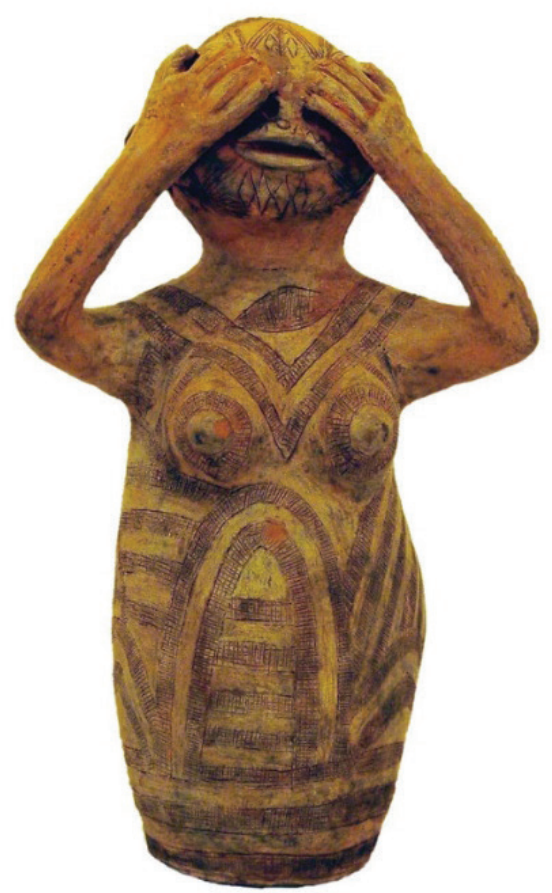

https://www.flickr.com/photos/105727602@N04/12981212064

Chiziane escreve, em Balada de amor ao vento:

As minhas mães, tias, avós, fecharam-me há uma semana nesta palhota tão quente e dizem que me preparam para o matrimónio. Falam do amor com os olhos embaciados, falam da vida com os corações dilacerados, falam do homem pelas chagas desferidas no corpo e na alma durante séculos, Sarnau, fecha a tua boca, esconde o teu sofrimento quando o homem dormir com a tua irmã mais nova mesmo na tua presença, fecha os olhos e não chores porque o homem não foi feito para uma só mulher. (CHIZIANE, 2003, p. 44).

A questão da poligamia, prática cultural tradicional que, na transição do modo de vida do meio rural para a sociedade moderna, gera ruídos e desequilíbrios, enunciada aqui no final deste trecho, é o tema principal do romance Niketche, publicado em 2002. Em entrevista (LABAN, 1998), Chiziane lamenta a situação das crianças que, devido à poligamia irresponsável masculina, acabam por ficar sem referências paternas, perdendo a possibilidade de conhecer parte de suas origens e suas famílias. Diante de pais ausentes, o encargo da criação dos filhos, como em muitas outras socie- 
dades, acaba por sobrecarregar as mulheres moçambicanas. Neste sentido, o romance de Chiziane, Niketche, coloca-nos diante de uma rede de mulheres, chefiadas por Ramy, a esposa oficial, que as faz agir em conjunto, em prol de suas autonomias financeiras, afetivas e sexuais.

\title{
O CORPO FEMININO - ALVO DA AGRESSÃO DO CORPO MASCULINO, EM DIFERENTES TERRITÓRIOS E CONTEXTOS
}

Em Cadernos de memórias coloniais temos o corpo feminino, alvo de ataques do mundo patriarcal, dentro e fora de casa, na infância e adolescência. $\mathrm{O}$ mesmo apelo ao silenciamento é feito à protagonista, na escrita de Isabela Figueiredo, pelas mulheres mais velhas, neste caso representadas pela avó. A narradora nos diz que, no único caminho possível para a escola secundária, em Caldas da Rainha, havia uma oficina:

\begin{abstract}
Não era uma porta, mas uma cloaca. Dentro, paredes negras de humidade e óleo velho. Escuridão. Quando passava frente ao portão, três homens atarracados, com mãos e roupas sujas do trabalho, gritavam-me imprecações sexuais que me esforçava por não ouvir. Colava o pescoço aos ombros, comprimia as paredes dos ouvidos, fechava os olhos, fechava-me, e mesmo sem querer escutava mamas, cona, rabo, palavras que vinham adornadas com advérbios ou verbos de péssima expressão. Impropriedades. Tinha 13 anos, e insultavam-me por evidenciar mamas, cona e rabo, não percebendo eu o desmerecimento. Insultavam-me por já ser uma mulher. (...) A minha avó era uma velhinha muito branca, no seu uniforme de viúva. Quando lhe descrevi o comportamento dos homens da garagem, disse-me que era assim, que não respondesse, que mulheres honradas tinham orelhas moucas. (FIGUEIREDO, 2017, p. 193).
\end{abstract}

A palavra cloaca, para designar a porta da oficina chama nossa atenção. A potência da imagem metafórica, da parte abjeta de corpo animal, contribui para a construção da imagem que fazemos daquele espaço. $\mathrm{O}$ adjetivo "atarracados", para os homens que habitam a cloaca, dão-nos uma imagem de corpos deformados. A tensão da jovem, que não tem outro caminho possível para se locomover para a escola, expressa-se no corpo: o pescoço colado ao ombro, os olhos cerrados, a tentativa de fechar os ouvidos. As palavras que estes corpos-machos emitem têm a intenção de insulto, enquanto esquartejam com palavras o jovem corpo feminino, discriminando suas partes: mamas, cona, rabo.

A violência contra meninas e mulheres, na obra de Figueiredo, não vem só destes homens-trabalhadores, do espaço da rua. Expressa-se também dentro de casa, na personagem de ti Gusto, que abusa das meninas que trabalham em sua garagem, modelando o barro.

O ti Gusto talvez gostasse do barro, mas do que ele gostava mesmo era de ter na garagem, à sua disposição, um ramalhete de meninas com os peitos duros e fresquinhos, umas mimosas, 
de face rosada e pele branca. Uns valos de leite doce, ainda morno, acabado de ordenhar às vaquinhas da fazenda. (FIGUEIREDO, 2017, p. 195).

Os peitos duros, as faces rosadas, as peles brancas, contrapõem-se à imagem do tio como suíno: "O ti Gusto era a lamentada fina-flor do drama e virtudes provincianas. Eu e as cabritinhas das terrinas conhecíamos-lhe outra missa, e, nela, o oficiante era um suíno de patilhas." (FIGUEIREDO, 2017, p. 197). O uso de metáforas animais e ligadas à natureza (como vaquinhas e ramalhetes), aparecem para descrever diferentes corpos, dando ao leitor sugestões sensórias bastante eficientes. Nestas construções literárias, Figueiredo evoca sensorialidades: cheiros, cores e impressões que estes corpos, em íntimo contato com o corpo da jovem narradora, causam-lhe.

Chiziane é contundente ao expor o corpo feminino como terreno para a violência e a violação, impingida pelos mais diferentes corpos masculinos que o tratam, no cenário da guerra, como se fosse a própria terra da qual devem se apossar pela força. E nesta sequência de abusos, as mulheres passam a sentir-se menos humanas, menos vivas, sucessivamente objetificadas no modo como são tratadas por estes outros masculinos, invasores de seus terrenos. Adrienne Rich, feminista, poeta e intelectual estadunidense, aborda o corpo como a geografia mais próxima, que precisa ser "reclamada", com suas histórias, marcas e características (2002, p.17). Tanto Rich como Chiziane apontam para o fato de que o corpo feminino precisa ser reivindicado, como uma espécie de direito humano, em contraposição aos que querem fazer dele usos espúrios, como se fosse território de ninguém. Ambas tratam da identidade, o corpo pessoal, e também de corpos políticos, coletivos, marginalizados, os corpos das mulheres. Chiziane revela, em entrevista (LABAN, 1998) que, em suas obras, abre mão do fantástico, do maravilhoso, a favor do testemunhal. Trata-se de um "eu-comunidade", na abordagem que faz de corpos que passaram pelas mesmas experiências.

Nós, mulheres, fazemos existir, mas não existimos. Fazemos viver, mas não vivemos. Fazemos nascer, mas não nascemos. Há dias conheci uma mulher do interior da Zambézia. Tem cinco filhos, já crescidos. O primeiro, um mulato esbelto, é dos portugueses que a violaram durante a guerra colonial. O segundo, um preto, elegante e forte como um guerreiro, é fruto de outra violação dos guerrilheiros de libertação da mesma guerra colonial. O terceiro, outro mulato, mimoso como um gato, é dos comandos rodesianos brancos, que arrasaram esta terra para aniquilar as bases dos guerrilheiros do Zimbabwe. O quarto é dos rebeldes que fizeram a guerra civil no interior do país. A primeira e a segunda vez foi violada, mas à terceira e à quarta entregou-se de livre vontade, porque se sentia especializada em violação sexual. O quinto é de um homem com quem se deitou por amor pela primeira vez. (CHIZIANE, 2002, p. 298). 
Para Griselda Pollock, intelectual dos estudos feministas pós-coloniais, a teoria crítica ${ }^{13}$ e a pós-estruturalista ${ }^{14}$ apostam na linguagem, no discurso e na subjetividade como termos-chave para o reconhecimento da imbricação do eu e do social (2002, p. 201). A autora ressalta que a subjetividade não se dá num espaço neutro, mas dentro de contextos sociais. Esta sobreposição entre o subjetivo e o coletivo está muito presente no modo como Chiziane concebe seu trabalho literário e explicita-se nas reflexões que faz sobre ele.

\section{ALTERIDADES-MÚLTIPLOSCORPOSEHISTÓRIASEMRELAÇÕES}

Tanto Chiziane como Sadimba revelam aprendizados que se deram pelo corpo, no quotidiano, em casa, na tradição, com as mulheres mais velhas, na família, com os ancestrais, e junto à natureza. Os corpos e as obras carregam histórias. Os objetos artísticos, feitos de materiais da natureza como a terra e os pigmentos, em diferentes cores e texturas, ao entrarem em contato com outros corpos, apreciadores daquilo que eles são e carregam em si, integram um todo.

Hélène Cixous, dramaturga, poetisa e crítica literária francesa relaciona, na seguinte citação, o fazer literário a elementos da natureza, numa escrita repleta de movimentos e sensorialidades.

Que escriba! Y su texto, buscándose, se conoce mas que carne y sangre, pasta amasándose, levantandose, insurreccional, con ingredientes sonoros, perfumados, combinación agitada de colores flotantes, follajes y ríos lanzándose al mar que alimentamos. (CIXOUS, 1995, p. 50).

No excerto acima, Cixous conclama à escrita como modo de constituição do sujeito, e a criação do texto se faz de carne, sangue e pasta, ou seja, através do trabalho manual e corporificado. O sentido da insurreição, que antecede uma série de ingredientes ancorados em diferentes sinestesias, terminam com o desaguar do rio ao mar. Um mar que não parece ser apenas natureza, mas caldo da cultura, feito do que nele projetamos. Cixous reflete, portanto, sobre o fazer literário de forma poética, libertadora e arrebatadora. Chiziane e Sadimba libertam-se das opressões sentidas na carne, por meio de seus trabalhos artísticos, encarnados deste sentido insurrecional apontado por Cixous.

Em diversas entrevistas, Chiziane autodenomina-se contadora de histórias e não romancista, influenciada que foi, em sua escrita, pelo mundo da oralidade e as narrativas ouvidas da boca da avó. Ao nosso ver, na oralidade, os corpos se encontram, olhos nos olhos, através das histórias da memória, vindas direto da cabeça, das vivências, do passado mítico e ritual. Ao tornar-se romancista, no entanto, temos, no caso de Chiziane, um fazer que sai da cabeça, do mundo das ideias e passa, necessariamente, pela mão, esta parte do corpo, e transpõe-se para o papel, e só fará sentido ao encontrar o corpo do outro, pelo olho, a leitura, e as histórias voltam então à cabeça. Destacamos assim que corpos e histórias instauram ciclos, circulações em que 
As questões da alma feminina não podem ser tratadas tentando-se esculpi-la de uma forma mais adequada a uma cultura inconsciente, nem é possível dobrá-la até que tenha um formato intelectual mais aceitável para aqueles que alegam ser os únicos detentores do consciente. Não. Foi isso o que já provocou a transformação de milhões de mulheres, que começaram como forças poderosas e naturais, em párias na sua própria cultura. Na verdade, a meta deve ser a recuperação e o resgate da bela forma psíquica natural da mulher. (ESTÉS, 1999, p. 9).

Clarissa Pinkola Estés (1945-), psicanalista e poeta estadunidense, posiciona o arquétipo da mulher selvagem enquanto força motriz do autoconhecimento feminino, generalizando a ideia de um anseio natural e saudável pelo que é selvagem ${ }^{15}$ (1999, p. 13), em conflito com uma sociedade que nos ensina a envergonhar-nos desta busca. Por intermédio de mitos e das histórias contadas e transmitidas como um legado, de geração em geração, no livro Mulheres que correm com os lobos, mitos e histórias do arquétipo da mulher selvagem ${ }^{16}$, a psique instintiva da mulher é resgatada e discutida numa espécie de escavação "psíquico-arqueológica" que remexe as "terras espirituais” (ESTÉS, 1999, p. 7) acossadas e devastadas historicamente, revertendo os ritmos impostos artificialmente. Estés identifica a invenção como a principal ocupação da mulher selvagem. A invenção que transpõe barreiras impostas, restaura os ciclos femininos e se manifesta através da linguagem, da criatividade e da arte. Chiziane, Sadimba e Figueiredo lançam-se, portanto, a esta "ocupação da mulher selvagem", a de serem criadoras, tantas vezes interdita às mulheres.

Paulina Chiziane, no prefácio ao livro de Isabela Figueiredo, escreve, logo ao início: "A tua obra, Caderno de memórias coloniais, faz a análise da história a partir de um lugar proibido às mulheres castas: o sexo." (CHIZIANE, 2017, p. 15). Chiziane agradece a Isabela este livro, ao contrapor estas duas visões ${ }^{17}$ : a das mulheres brancas e das mulheres negras, durante o colonialismo, e os homens entre elas, as opressões de tantos lados.

Estávamos eu e tu, cada uma no seu lado da barricada, quando o colonialismo aconteceu. Tu, branca, filha de um colono racista e eu, negra, filha de um colonizado, também racista. (...) De bordados e de receitas de cozinha me é permitido falar, mas não sei bordar nem cozinhar. Falar de sexo é tabu. (...) Ah, mas se eu pudesse, contar-te-ia mil e uma histórias maliciosas, picantes, saídas das bocas das mulheres negras. (CHIZIANE, 2017, p. 16). ${ }^{18}$

A autora moçambicana destaca que o racismo estava dos dois lados: entre os colonizadores e os colonizados. Elenca os assuntos ditos "permitidos" às mulheres, atribuídos tradicionalmente a elas, como a cozinha e o bordado, com os quais Chiziane diz não ter afinidade alguma. E quando enuncia que poderia contar à amiga branca histórias sobre sexo, consideradas tabu, que corriam entre as bocas das mulheres negras, cria com sua interlocutora branca uma afinidade transgressora; pela possibilidade imaginada de estarem, ambas, a partilhar histórias ${ }^{19}$, e não "cada uma no seu lado da barricada". 
Paulina Chiziane, ao mencionar que poderia contar "mil e uma histórias", faz-nos lembrar de Sherazade ${ }^{20}$ e sua capacidade resistente de salvar a própria vida, por ser uma narradora astuta. Ao cativar a audiência, noite após noite, em narrativas de histórias que abordam as experiências humanas, quem sabe até "maliciosas, picantes", como adjetiva a autora moçambicana, possibilita a cura do impulso assassino do sultão. Chiziane e Sherazade irmanam-se, portanto, ao desafiarem os poderes patriarcais e adotarem a atitude revolucionária de salvar a própria vida pela enunciação de narrativas.

Neste prefácio, em tom de confidência epistolar, Chiziane revela intimidades da comunidade feminina negra, da qual fazia parte, no contexto colonial, dando a ver, ao leitor, um ponto de vista pouco divulgado. Traz à tona o que pensavam as mulheres negras sobre os homens negros e brancos e sobre as mulheres brancas, destacando as diferenças entre os corpos e as relações que se instauravam, no contexto colonial. A dor e o prazer estão associados, aqui, aos conflitos que emergem das relações afetivas e sexuais interétnicas, interculturais e inter-raciais.

Entre cervejas e risos elas gozavam com os brancos e brancas. Diziam elas que homem branco é dinheiro. Homem preto é gosto, é prazer. Deixa que esses brancos nos deem o dinheiro que precisamos para alimentar as crianças. Mulher branca é o quê? As mulheres brancas não têm à frente, não têm atrás, são lisas e frias como madeira seca. É por isso que os maridos delas, quando querem chorar como crianças, vêm a correr para os nossos braços. Nós somos bem recheadas à frente, atrás, e das mulheres macuas então, nem se fala! Estão bem recheadas por baixo das pernas, como um bolo de creme, porque alongam os genitais. (...) Pobres mulheres brancas! Elas dormem sozinhas, na cama fria, enquanto os maridos gozam o prazer de viver nos nossos braços. (CHIZIANE, 2017, p. 16).

Rich alerta que " $[. .$.$] os sentimentos brancos mantêm-se no centro.$ E eu, claro, preciso de sair da base e do centro dos meus sentimentos, mas com um sentido de correcção de que os meus sentimentos não são o centro do feminismo" (2002, p. 34). Rich argumenta no sentido de demolir uma visão única, eurocêntrica, ou estadunidocêntrica do mundo, se quisermos ser mais específicas. Chiziane, por sua vez, levanta sua voz, trazendo à tona as diferenças sociais e sexuais que atingiam os corpos femininos brancos e negros, no contexto colonial moçambicano. Ao entrarmos em contato com os textos de Chiziane, vemos a exposição das experiências e dos sentimentos das mulheres negras, muitas vezes silenciadas, proibidas de falar.

Rich, Chiziane e Cixous revelam seus lugares de fala ${ }^{21}$ e ponderam para a consideração do ponto de vista do outro. Conclamam leitores e leitoras para esse movimento simultâneo, de olhar para dentro e olhar para fora, possibilitando a ampliação de visões, numa perspectiva mais relacional e menos colonialista. O movimento, no encontro com o outro, é que abre espaço para transformações. A escrita inscreve-se, no caso das três autoras, como trabalho construtivo para a geração de impulsos de vida, no combate aos impulsos de morte. 


\section{Como escreve Cixous,}

[...] escribir es trabajar; ser trabajado; (en) el entre, cuestionar (y dejarse cuestionar) el proceso del mismo $y$ del otro sin el que nada esta vivo; deshacer el trabajo de la muerte, deseando el conjunto de uno-con-el-otro, dinamizado al infinito por un incesante intercambio entre un sujeto y otro; sólo se conocen y se reinician a partir de lo más lejano - de sí mismo, del otro, del otro en mi. Recorrido multiplicador de miles de transformaciones. (CIXOUS, 1995, p. 47).

\section{ÚLTIMAS REFLEXÕES}

Os prêmios recebidos por Chiziane e Figueiredo, por suas obras, destacam a relevância dos temas abordados, bem como a maneira própria como trabalham com a linguagem literária. O reconhecimento de Sadimba, com exposições e obras em galerias de vários países, revela a potência que emerge de suas figuras, um tanto humanas, um tanto míticas.

As obras das três artistas, destacadas neste artigo, são denúncias de corpos resistentes, e são também trabalhos autorais, ficcionais, que se inserem num projeto artístico maior, que engloba um conjunto de obras de cada uma delas, dando-lhes assim uma potência que a limitação do espaço de um artigo talvez não seja capaz de abarcar.

Encerramos este estudo sem respostas prontas, mas com palavras que nos fazem pensar, diante dos contextos atuais.

A viagem para o futuro exige sempre uma paragem, um olhar para trás. [...] Que ganhamos nós com a violência do colonialismo? E o que é que perdemos? Construiu-se uma civilização de terror e ódio entre os povos. De genocídio dos índios na América e dos negros em África. Criou-se um mundo de dor, de terror e de crimes sem fim. Será que para construir uma civilização é preciso matar, violentar, torturar? (CHIZIANE, 2017, pp. 21-22).

Mais uma vez vemos Moçambique envolto numa atmosfera de morte: alternam-se os atores que engendram a violência, e a população segue sendo vítima de ataques e interesses espúrios, que ceifam vidas e a possibilidade de dias melhores. Meninas e mulheres continuam a ser as mais vulneráveis, neste cenário distópico. ${ }^{22}$ Fazemos nossas as palavras de Chiziane, a fim de prosseguirmos na esperança de tempos mais serenos: "Trabalhar numa atmosfera de morte é minha forma de resistir. Ninguém tem o direito de interromper os meus sonhos." (CHIZIANE, 2013, p. 205).

\section{REFERÊNCIAS}

ANZALDÚA, Gloria. Como domesticar uma língua selvagem. In: MACEDO, Ana Gabriela (org.). Estudos comparatistas e cosmopolitismo: pós-colonialidade, tradução, arte e género. Braga: Universidade do Minho, CEHUM, 2017. p. 225-238. Disponível em: http://repositorium.sdum.uminho.pt/ handle/1822/59751. Acesso em: 28 nov. 2020. 
CHIZIANE, Paulina. Niketche - Uma história de poligamia. Alfragide: Caminho, 2002.

Balada de amor ao vento. Lisboa: Caminho, 2003.

. Eu, Mulher... Por uma nova visão do mundo. In: Abril - Revista do Núcleo de Estudos de Literatura Portuguesa e Africana da UFF, Vol. 5, no10, p. 199-205, Abril de 2013.

Prefácio. In: Figueiredo, Isabela. Caderno de memórias coloniais. $7^{\text {a }}$ ed. Alfragide: Caminho, 2017.

CIXOUS, Hélène. La risa de la medusa: ensayos sobre la escritura. Prólogo y traducción Ana Maria Moix; traducción revisada Myriam Díaz-Diocaretz. Barcelona: Anthropos; Madrid: Comunidad de Madrid. Consejería de Educación. Dirección General de la Mujer; San Juan: Universidad de Puerto Rico, 1995.

ESTÉS, Clarissa Pinkola. Mulheres que correm com os lobos: mitos e histórias do arquétipo da mulher selvagem. Rio de Janeiro: Rocco,1999.

FIGUEIREDO, Isabela. Caderno de memórias coloniais. $7^{\text {a }}$ ed. Alfragide: Caminho, 2017.

JONES, Ann Rosalind. Escrever o corpo: para uma compreensão de l'écriture féminine. Tradução Maria Filomena Louro. In: MACEDO, Ana Gabriela (org.). Gênero, Identidade e Desejo. Lisboa: Edições Cotovia, 2002. p. 75-95.

KAUR, Rupi. Outros jeitos de usar a boca. Rio de Janeiro: Editora Planeta do Brasil, 2017.

KILOMBA, Grada. Memórias da plantação - episódios de racismo quotidiano. Tradução de Jess Oliveira.1ª ed. Rio de Janeiro: Cobogó, 2019.

LABAN, Michel. Moçambique: encontro com escritores. v. III. Porto: Fundação Eng. António de Almeida, 1998.

POLLOCK, Griselda. A política da teoria: gerações e geografias na teoria feminista e na história das histórias de arte. Tradução Ana Gabriela Macedo e Maria Amélia Carvalho. In: MACEDO, Ana Gabriela (org.). Gênero, Identidade e Desejo. Lisboa: Edições Cotovia, 2002. p. 191-220.

RICH, Adrienne. Notas para uma política da localização. Tradução Maria José da Silva Gomes. In: MACEDO, Ana Gabriela (org.). Gênero, Identidade e Desejo. Lisboa: Edições Cotovia, 2002. p. 15-35.

Recebido para avaliação em 30/11/2020 Aprovado para publicação em 22/01/2021

\section{NOTAS}

1 Renata Flaiban Zanete é doutoranda em Modernidades Comparadas, no Centro de Estudos Humanísticos do Instituto de Letras e Ciências Humanas da Universidade do Minho. Integrante do grupo de investigação em Gênero, Artes e Estudos Pós-Coloniais. 
Mestre em Linguagem e Educação pela Faculdade de Educação da Universidade de São Paulo. Fundadora da Companhia Rodamoinho de teatro. Atriz e professora de teatro no Agrupamento de escolas de Prado, Portugal. ORCID: 0000-0002-5241-7823

2 Viviane Ferreira de Almeida é doutoranda em Estudos Culturais no Instituto de Ciências Sociais e Instituto de Letras e Ciências Humanas da Universidade do Minho e mestre em Educação Social e Intervenção Comunitária pelo Instituto Politécnico de Lisboa - Escola Superior de Educação de Lisboa. Mediadora cultural e literária, dinamiza oficinas de Escrita Criativa no Brasil e em Portugal. ORCID: 0000-0002-3779-4890

3 As primeiras aproximações às obras das autoras analisadas no presente artigo surgiram durante o projeto Escola de Verão - Comunicação e Cultura para o Desenvolvimento, realizado no Centro de Estudos de Comunicação e Sociedade (CECS), do ICS-Uminho, em meados de 2020, no qual as autoras foram bolseiras de investigação FCT. À Doutora em Ciências da Comunicação, professora Lurdes Macedo, coordenadora do projeto, as autoras fazem um agradecimento, pela partilha de experiências e vivências desenvolvidas por ela em Moçambique.

4 Grupo étnico bantu, os macondes são um povo dividido pelo rio Rovuma, vivendo no nordeste de Moçambique e no sudeste da Tanzânia. Os de Moçambique constituem dois grupos distintos, os da terra baixa e os dos planaltos. Salientamos que as duas grafias são aceites, referindo-se à mesma etnia: maconde, na escrita em língua portuguesa, e makonde, nas tradições africanas. LARANJEIRA, Lia Dias. Migração makonde, produção de esculturas e mercado de arte no Tanganyika: a questão do estilo Shetani (1950-60). Anais do Museu paulista, São Paulo, v. 25, n. 2, p. 141-162, ago. 2017 . Disponível em: http:// www.scielo.br/scielo.php?script=sci_arttext\&pid=S010147142017000200141\&lng=en\&nr m=iso. Acesso em:_ 31 dez. 2020. DOI: 10.1590/1982-02672017v25n02d06.

5 A Frente de Libertação de Moçambique foi um movimento anticolonialista, formalizado como partido político em 1962 e o primeiro partido que assumiu o governo, terminado o período colonial em Moçambique, em 1975.

6 Disponível em: https:/www.publico.pt/2009/12/23/culturaipsilon/noticia/isabela-figueiredo-quoto-colonialismo-era-o-meu-paiquot-247765. Acesso em: 23 nov. 2020.

7 Adorno usado pelas mulheres macondes no lábio superior.

8 "A mulher que não quer ter cabeça”; "A mulher que está grávida de um filho fora do casamento"; "A mulher que vai buscar água e leva o filho Samuel às costas, recusando-se a deixá-lo com outra mulher” são alguns dos personagens de Reinata Sadimba que contam histórias. Disponível em: https://gulbenkian.pt/noticias/mulheres-do-barro/. Acesso em: 28 nov. 2020.

9 Disponível em: http://novomundoperfeito.blogspot.com/2014/07/cartografia-do-meu-corpo.html. Acesso em: 25 nov. 2020.

10 A este respeito, convoca-se a obra da poeta contemporânea indiana Rupi Kaur que propõe uma reflexão, um tocar na ferida em temas como a dor, o amor, a ruptura e a cura. Em Outros jeitos de usar a boca a autora fala do trauma do corpo feminino, sendo explícita ao afirmar que a escrita do livro foi uma resposta do seu coração perante a súplica do seu sofrimento: "meu coração me acordou chorando ontem à noite, o que posso fazer eu supliquei, meu coração disse, escreva o livro”. (KAUR, 2017, s/p.).

11 Grada Kilomba exemplifica esta afirmação com recurso a imagem e biografia de Anastácia, "Escrava Anastácia”, cujos relatos indiciam que foi obrigada a usar um colar de ferro bastante pesado e uma máscara facial que impedia a sua comunicação verbal. Embora as razões desta imposição sejam variáveis, podemos concluir que todas estão intimamente ligadas ao poder e a necessidade de calar a voz de Anastácia.

12 Disponível em: https:/www.dn.pt/cultura/grada-kilomba-ainda-hoje-glorificamos-e-romantizamos-o-colonialismo-10931583.html. Acesso em: 25 nov. 20.

13 A teoria crítica, desenvolvida pela Escola de Frankfurt, desde os anos 30 do século XX, preconiza não só a compreensão da sociedade, mas a transformação dela, por meio de teorias emancipadoras. Ver: FISCHER-LESCANO, Andreas. A teoria crítica dos sistemas da escola de Frankfurt. Novos estudos - CEBRAP, São Paulo, n. 86, p. 163-177, mar. 2010. Disponível em: http://www.scielo.br/scielo.php?script=sci_arttext\&pid=S0101-33002010000100009\&ln g=en\&nrm=iso. Acesso em: 02 jan. 2021. DOI: 10.1590/S0101-33002010000100009. 
14 Quanto ao pós-estruturalismo temos, desde os anos 60 do século XX, uma aposta no estudo das produções e objetos artísticos por meio de entrecruzamentos disciplinares, advindos dos estudos da linguagem, da psicanálise, da literatura, da filosofia, em prol de múltiplas leituras e da valorização da recepção. Disponível em: https://edtl.fcsh.unl.pt/ encyclopedia/posestruturalismo/ Acesso em: 02 jan. 2021.

15 A autora define a palavra selvagem "em seu sentido original, de viver uma vida natural, uma vida em que a criatura tenha uma integridade inata e limites saudáveis." (1999, pp. 10-11).

16 Partindo de um estudo comparativo entre os lobos e as mulheres, a autora identifica, entre os saudáveis, características psíquicas comuns como: "percepção aguçada, espírito brincalhão e uma elevada capacidade para a devoção.” (Estés, 1999, p. 7). Para além de uma inata capacidade para a adaptação, coragem e um sentido gregário.

17 Em semelhança de propósito citamos a residência artística promovida pela Fundação Calouste Gulbenkian, na Bajouca, concelho de Leiria, Portugal, em outubro de 2020, que reuniu saberes e fazeres do ofício da escultura entre artistas negras e brancas: Reinata Sadimba e Merina Amade, moçambicanas, e Céu Pedrosa, portuguesa. Disponível em: https:// gulbenkian.pt/noticias/mulheres-do-barro/. Acesso em: 28 nov. 2020.

18 Chiziane registra todo o prefácio do livro de Figueiredo em itálico. No entanto, retiramo-lo aqui para adequação às normas desta publicação.

19 Ver: LARROSA, Jorge. Experiência e Alteridade em Educação. Revista Reflexão e Ação, Santa Cruz do Sul, v. 19, n. 2, p. 04-27, jul. 2011. Disponível em: https://online.unisc.br/seer/ index.php/reflex/article/view/2444. Acesso em: 02 jan. 2021. DOI: 10.17058/rea.v19i2.2444.

20 Ver: HADDAD, Jamil Almansur. Interpretações das Mil e Uma Noites. Revista Internacional d'Humanitats 48 CEMOrOc-Feusp / Univ. Autònoma de Barcelona, p. 43-48, jan-abr 2020. Disponível em: http://www.hottopos.com/rih48/43-48jamyl.pdf. Acesso em: 02 jan. 2021.

21 Ver: RIBEIRO, Djamila. O que é lugar de fala? Belo Horizonte: Letramento, 2017.

22 Disponível em: https://observador.pt/2020/11/24/ataques-a-mocambique-casamentos-forcados-aos-11-anos-para-sobreviver/. Acesso em: 29 nov. 2020. 